This is the peer reviewed version of the following article: Nimbley, E, Caes, L, Jones, A, Fisher, E, Noel, M, Jordan, A. A linguistic analysis of future narratives in adolescents with Complex Regional Pain Syndrome and their pain-free peers. European Journal of Pain 2021; 25: 693-703, which has been published in final form a https://doi.org/10.1002/ejp.1704 This article may be used for non-commercial purposes in accordance with Wiley Terms and Conditions for self-archiving.

\title{
A linguistic analysis of future narratives in adolescents with Complex Regional Pain Syndrome and their pain-free peers.
}

Running head: Linguistic analysis of adolescent CRPS future narratives

Emy Nimbley, $\mathrm{MSc}^{1}$, Line Caes, $\mathrm{PhD}^{2}$, Abigail Jones, $\mathrm{MSc}^{1,3}, \mathrm{PhD}^{3}$, Emma Fisher, $\mathrm{PhD}^{3,4}$ Melanie Noel, $\mathrm{PhD}^{5}$, Abbie Jordan, $\mathrm{PhD}^{1,3}$

${ }^{1}$ Department of Psychology, University of Bath, UK;

${ }^{2}$ Division of Natural Sciences, University of Stirling, UK;

${ }^{3}$ Centre for Pain Research, University of Bath, UK;

${ }^{4}$ Department for Health, University of Bath, UK;

${ }^{5}$ Department of Psychology, University of Calgary; Alberta Children's Hospital Research Institute and Hotchkiss Brain Institute, Canada;

\section{Corresponding Author:}

Abbie Jordan, $\mathrm{PhD}$

Department of Psychology and Centre for Pain Research, University of Bath; Claverton

Down, Bath BA2 7AY, UK; Telephone: 0044 (0)1225-386982;

Email: a.1.jordan@ bath.ac.uk

Article category: Original article

Funding sources: This work was supported by the Pain Relief Foundation and the Rare Diseases Foundation.

\section{Statement of significance:}

Social comparisons are commonly undertaken by adolescents with CRPS in relation to peers, increasing risk for poor cognitive, affective and social outcomes. Findings promote the potential importance of targeting psychosocial factors in treatments for paediatric chronic pain. 


\begin{abstract}
Background. Complex Regional Pain Syndrome (CRPS) is a chronic pain condition that often develops after injury, with a typical onset in adolescence. The impact of chronic pain is far-reaching, with many adolescents reporting atypical developmental trajectories compared with peers. Social Comparison Theory offers a framework for understanding how such comparisons influence wellbeing, whereby a heightened sense of disparity places adolescents at risk of poor cognitive, affective and social outcomes. Using a novel linguistic analysis programme, this study aims to investigate cognitive, affective and social language used by adolescents with CRPS in comparison to their peers during a task reflecting on their futures.
\end{abstract}

Methods. A story completion task was completed by adolescents with CPRS ( $\mathrm{n}=49)$ and adolescents without pain $(n=48)$. This task involved asking adolescents to describe their imagined future. Narratives were analysed using a novel linguistic analysis programme, focusing on the cognitive, affective and social dimensions.

Results. Findings revealed significant group differences in how adolescents with CRPS described their imagined futures. Adolescents with CRPS used significantly fewer positive affect and more negative affect, anger and sadness words, and greater insight and discrepancy words. No significant groups differences were found for social words.

Conclusions. Substantial differences in cognitive and affective words were found between adolescents with and without CRPS. Findings provide novel insights into current understandings of cognitive, affective and social processes in adolescents living with chronic pain, particularly with regard to adolescent developmental trajectories, and may in turn highlight potential targets in psychosocial interventions for adolescents living with chronic pain.

\title{
Introduction
}

Complex Regional Pain Syndrome (CRPS) is a localised chronic pain condition, typically occurring after injury and involving pain in the extremities. Peak onset of CRPS occurs during adolescence, (Abu-Arafeh \& Abu-Arafeh, 2017) a developmentally sensitive period when pain-associated disability is particularly challenging and associated with alterations in autonomy, independence, and identity (Jordan et al., 2018). Adolescence is also a critical period for developing future perceptions, something often disrupted in those with chronic pain due to heightened uncertainty (Massey et al., 2008). Additionally, during adolescence, the dominance of social relationships (particularly peer relationships) becomes more prominent (Guassi et al., 2018). Managing social relationships can be 
difficult for adolescents with chronic pain, who commonly report disrupted social development (Eccleston et al., 2008; Jordan et al., 2018). Little is known about social development in specific chronic pain conditions, with a notable lack of literature exploring social development in adolescents who have CRPS (Jones et al., in press). Given the unique presentation of adolescent CRPS, such as elevated pain levels and pain-related fears compared with other pain conditions (Logan et al., 2013; Simons, 2017), it is important for research to explore the specific social developmental experiences of this population.

Social Comparison Theory provides a comprehensive framework for understanding how comparisons may influence wellbeing in adolescents with chronic pain. According to Festinger's (1965) theory, when individuals experience states of uncertainty, they are motivated to compare self functioning by comparison with others. Outcomes of such comparisons is dependent on whether the adolescent identifies with, or contrasts with their peers (Buunk \& Gibbons, 1997; 2007). Social comparisons are frequently observed in individuals with chronic pain, where uncertainty associated with living with pain is frequently reported. Specifically, perceived discrepancies have been found to be associated with impaired wellbeing, such as increased negative affect and poor self-esteem (Arigo et al., 2014). It is therefore plausible that chronic pain influences social comparison through a sense of heightened disparity to peers, increasing the risk for poor outcomes across domains.

Narrative and language are important sources of information regarding the individual's beliefs and perceptions in chronic pain research (Candib, 2004; Noel et al., 2016). Recent advances in computerized linguistic analysis programmes demonstrate their utility as a naturalistic method of examining people's health experiences across domains (Pennebaker, 1996; Tausczik \& Pennebaker, 2010). The application of linguistic analysis in chronic pain research has demonstrated potential in reflecting both the nature and the underlying processes involved in living with pain (Junghaeunel et al., 2017; Langer et al., 2016). These studies however have failed to examine the broader context of pain, focusing solely on language use in relation to cognitive factors (e.g. catastrophizing). This study aims to address this gap by including affective and social dimensions of adolescent's language use when describing their imagined futures. Given evidence of the influence of social comparison across cognitive, affective and social domains, we hypothesized that adolescents with CRPS would use more cognitive and negative affect words, and fewer positive affect and social words, compared with adolescents without chronic pain.

\section{Methods}

This study adopted a between-subjects, cross-sectional design to compare cognitive, affective and social language used by adolescents with complex regional pain syndrome (CRPS) and adolescents 
without chronic pain when writing about their imagined future. We used data collected as part of a larger project exploring future perceptions in adolescents with CRPS and their parents, the full protocol of which is reported and registered on the Open Science Framework via https://osf.io/r2wsc/.

\section{Procedure}

Participants with CRPS were recruited through CRPS-specific charities and organizations who advertised the study via newsletters, emails and online forum or blog posts. Adolescents without chronic pain were recruited via advertisements to local school and community centres, as well as on social media platforms such as Twitter. We recruited participants between May 2018 and September 2019. Study eligibility criteria required participants to be aged between $14-25$ years old. This definition of adolescence is congruent with Sawyer and colleagues' recent call for adolescence to be extended until 25 years to account for delays in achievement of social milestones (e.g. moving out of the family home) and structural brain changes that occur into the early-mid 20s (Sawyer, Azzopardi, Wichremarathne \& Patton, 2018). Further eligibility criteria required participants to: (1) have no severe mental health condition e.g. psychosis; (2) have the capacity to provide informed consent; (3) be fluent in English; and (4) have access to the internet. For the sample of adolescents with CRPS, an additional eligibility criterion included a self-reported formal diagnosis of CRPS, which was confirmed by the participant during initial email screening prior to taking part in the study. For the sample of adolescents without pain, an additional eligibility criterion included a self-report of not experiencing chronic pain (defined as pain occurring on most days in the past 3 months). These criteria were confirmed by the participant during initial email conversations prior to taking part in the study. Following the completion of study tasks, participant responses were screened to confirm eligibility. This screening did not result in the exclusion of any adolescents for any of the above criteria, however three responses (one from the CRPS sample and two from the pain-free sample) were excluded due to incompleteness.

The study was conducted using Qualtrics (2019), an online survey platform. Interested participants were contacted with relevant study information via email and screened for participation prior to a survey link being sent. For eligible adolescents under 16 years of age, parental consent was required and recorded before the survey link was sent to the adolescent via email. After obtaining consent, participants were provided with a demographic questionnaire, including questions regarding age and sex. Participants in the CRPS group were also required to provide the amount of time since they received a diagnosis of CRPS. Following this, participants were asked to complete the main study tasks. At the end of the study tasks, participants were provided with a final debrief screen and thanked for their participation. Participants were thanked for their time with a $£ 15$ Amazon shopping voucher. 


\section{Participants}

The sample of adolescents with CRPS comprised 50 participants, however at the time of analysis one participant response had to be excluded due to incorrect completion of the task, leaving a final sample size of 49. In the adolescents without chronic pain group (from now on referred to as the pain-free comparison sample), two participants were excluded from analysis due to incomplete responses, with a final sample size of 48 (see Table 1 for demographic characteristics for both participant groups). Ethical approval for the wider project was granted by the relevant university institutional research ethical review boards.

Insert Table 1 about here

\section{Story Completion}

The current study used a story completion task (Clarke et al., 2017), which is a useful method of collecting participant perceptions about sensitive topics and has previously been used with adolescent participants (Clarke et al., 2015; Walsh \& Mason, 2010; Frith et al., 2013). Consequently, story completion is a helpful method for collecting narrative data concerning perceptions of an imagined future of adolescents with an unpredictable long-term health condition such as CRPS. Living with chronic pain is often fraught with uncertainty and can lead to the loss of the individuals perceived destination (Wright et al., 2010; Frank, 1993). In this study, the story completion instructions were carefully written to trigger self-referent thinking by asking the adolescent to reflect on their expectations of their imagined future life by writing a story following the stem: "Imagine that it has been 10 years since you graduated from secondary school. You are at your high school reunion and hearing what friends have been doing since you finished school. What will your story look like?" A deliberate effort was made to keep instructions broad in terms of the type of story individuals may wish to write about (e.g. whether this included pain or not for those participants with CRPS and the role of other people in this story) in order to not direct the responses in any way. Participants were asked to write at least 10 lines for the future story to ensure that data sufficient for analyses were produced, with a 900-character minimum set (Clarke et al., 2017). Any response below this length was deemed an incomplete response and excluded from analyses.

A secondary school reunion was chosen for this current task due to school being a universally socially salient context for adolescents. For adolescents living with chronic pain, school settings additionally offer a prime social context where pain can cause significant interference, most notably through school attendance and attainment, which in turn can negatively affect social functioning (Logan et al., 2008; Jones et al., 2018). Thus, it is expected that the imagined high school reunion will trigger important cognitions, emotions and perceived social differences between the adolescent with CPRS and their peers. 
The story completion design involved careful consideration of a number of elements, including length of stem, authenticity of stem and amount of detail, adhering to published recommendations (Clarke et al., 2017). For example, the story stem was carefully worded to avoid inducing an illness narrative through its exclusion of a direct reference to CRPS, and therefore was universally applicable across both populations. Examples of stories from both samples can be found in Figures 1 and 2 .

Insert Figures 1 and 2 about here

Sample size for the broader qualitative story completion data was informed by existing literature concerning the use of story completion methods which suggests that samples can range from 20 to 200 participants (Clarke et al. 2019). However, samples on the larger end of this scale are relatively rare, with studies typically recruiting 40-60 participants (e.g. Clarke et al., 2015, Clarke et al., 2017, Hayfield \& Wood, 2018). Additionally, such samples tend to be drawn from a substantially larger populations (i.e. English speaking adults compared to adolescents who have CRPS). Thus, the current study's sample size is congruent with typically recruited sample sizes in story completion research.

\section{Linguistic Coding}

The future story completion tasks for both groups were coded using the Linguistic Inquiry and Word Count (LIWC; Pennebaker et al., 2015). LIWC is a linguistic analysis programme that processes and categorizes entered words by matching them against an extensive dictionary of over 6,500 words, generating the percentages or frequency of words across 90 categories. While this number of words appears initially modest in comparison to the estimated 100,000 words used in the English vocabulary, the LIWC dictionary was initially developed to focus on two broad categories of words that were identified to reflect these processes; content words, (e.g. nouns, verbs, adjectives, etc.) and style or function words (e.g. pronouns, propositions, conjunctions, etc.). This was due to the fact that developers identified these types of words as those that would reflect the LIWC's aim of developing an efficient system to successfully identify different psychological processes often studied in social and health psychology. The 90 language categories of the LIWC have subsequently been linked to various psychological processes across hundreds of studies, such as positive and negative emotions, social relationships and cognitive mechanisms. For example, the use of insight and causal words have previously been associated with the cognitive process of reappraisal, while positive emotion words have been consistently found to accurately reflect positive events and negative emotion words accurately reflect negative events (see Tauzczik \& Pennebaker (2010) for summary of development and findings). Since the original first version of LIWC in 2001, a significant number of studies have found the LIWC categories to be valid and reliable, with consistently high internal reliability, content and construct validity, and demonstrating superior validity in comparison to other computerized 
linguistic analysis programmes (Pennebaker, 2001;2007;2015; Tauzczik \& Pennebaker, 2010; Bantum \& Owen, 2009).

A total of 17 of the 90 LIWC dimensions were selected for analysis in this study, falling under three broad dimensions of cognitive, affective and social words. Cognitive, affect and social dimensions were carefully chosen based on previous literature exploring social comparison theory in the context of chronic illness, the robust relationship between these language categories and their relevant psychosocial processes using the LIWC, and the associated risk of poor outcomes across these domains for adolescents living with chronic pain (Festinger, 1965; Tauzczik \& Pennebaker, 2010; Arigo et al., 2014). The total number of cognitive, affective and social words were coded by the LIWC. With regard to the cognitive dimensions, words were coded relating to all chosen subcategories of insight, causal, discrepancies, tentative, certainty and differentiation. The affect dimension was further broken down into all chosen subcategories of negative emotions, anxiety, anger, sadness, or positive emotions. Finally, in the social category, words were coded relating to all chosen subcategories of family, friends, male and female (see Table 2 for definitions and example words from each LIWC dimension and subcategory.)

Insert Table 2 about here

\section{Data Analysis}

Following the coding of the imagined future tasks using the LIWC, data analysis was conducted using SPSS. T-tests were conducted between groups to detect any significant sex or age differences. Descriptive analyses (means, standard deviations, minimum and maximum) were conducted for all relevant variables. Group differences across cognitive, affective and social dimensions were analysed using one-way ANOVA's.

\section{Results}

No significant sex or age differences were found between groups. One-way ANOVA's were conducted on the cognitive, affect and social LIWC dimensions to compare the group differences between the future narratives of adolescents with CRPS and adolescents without chronic pain. The assumption of homogeneity was found to be violated, so a Welch test was conducted and interpreted. A summary of descriptive statistics for each linguistic category can be found in Table 3 .

Insert Table 3 about here 
With regard to the cognitive dimension, a statistically significant difference was found for total cognitive words $(\mathrm{F}(1,88.57)=15.59=\mathrm{p}=.000)$. On closer inspection, the cognitive subcategories of insight $(\mathrm{F}(1,86.87)=5.14, \mathrm{p}=.026)$ and discrepancies $(\mathrm{F}(1,95)=32.76, \mathrm{p}=.000)$ were found to be significant, with adolescents with CRPS using more words pertaining to insight and discrepancies than their peers without chronic pain. Cognitive subcategories of tentative, certainty and differentiation were not found to be statistically significant.

With regard to affective dimensions, there was no significant difference for the total number of affect words, however a significant difference was found for both subcategories of the dimension: positive emotions $(\mathrm{F}(1,68.45)=6.65, \mathrm{p}=.012)$ and negative emotions $(\mathrm{F}(1,94.20)=16.47, \mathrm{p}=.000)$, with adolescents with CRPS using fewer positive affect words and more negative affect words. Adolescents with CRPS also used significantly more anger $(\mathrm{F}(1,60.67)=8.20, \mathrm{p}=.006)$ and sadness $(\mathrm{F}(1,92.04)=4.72, \mathrm{p}=.032)$ words. Interestingly, the only affect LIWC variable found to be nonsignificant was that of anxiety.

Finally, neither total social words nor the four social subcategories scores (family, friends, male and female) were found to significantly differ between groups.

\section{Discussion}

The current study examined the cognitive, affective and social language used by adolescents with CRPS and their peers without pain when describing their imagined futures. Using a novel linguistic analysis programme, our results showed that adolescents with CRPS used fewer positive affect words, more negative affect words and more insight and discrepancies words. No evidence was found to suggest that adolescents with CRPS used fewer social words. Thus, the study's hypotheses regarding cognitive and affective word use was supported, while our hypothesis regarding social words was rejected. These findings provide novel contributions to our current understanding of the underlying cognitive, affective and social dimensions in adolescent's living with CRPS, particularly in the context of normative adolescent development.

Our current finding that adolescents with CRPS used fewer positive affect and a greater number of negative affect words is congruent with pediatric pain literature. Several reviews have highlighted the relationship between pain and negative affect, emphasizing the integral role of affect in assessment and treatment of chronic pain (Lumley et al, 2011; Liossi \& Howard, 2016). The current study also builds on previous LIWC studies that found greater verbal expression of negative affect was associated with pain catastrophizing in children with chronic pain (Langer et al, 2016), suggesting that negative affect is prevalent in chronic pain, independent of pain catastrophizing. Only a handful of 
studies have investigated social comparison in the context of long-term conditions, reviewed in Arigo et al.'s (2014) research synthesis, where authors concluded that negative affect was often caused by social comparisons. It is important to note however that these studies looked at comparisons amongst groups of individuals with long-term conditions as opposed to with healthy peers, and the underlying processes behind these comparisons are likely to differ. A further limitation of this review is that only 5 out of 37 studies focused on chronic pain, with all 5 studies comprising individuals with rheumatoid arthritis. Future studies could focus on exploring a broader range of chronic pain conditions, as living with chronic pain is a unique experience to other long-term conditions and thus the influence of social comparison in these populations may be similarly unique.

Interestingly, the only affect subcategory not to differ significantly between groups was anxiety. This is initially a counterintuitive finding, given that anxiety is a well-documented comorbidity in paediatric chronic pain with a distinct influence on functional outcomes (Tran et al., 2015). A possible explanation for our null finding is the elevated levels of anxiety observed in adolescence regardless of pain. It is estimated that between $15 \%$ and $20 \%$ of adolescent's experience anxiety at a clinically significant level (Whery et al., 2015). The future-orientated nature of the task could additionally influence this finding. Adolescence is a unique period with regards to future perceptions, with adolescents often displaying 'future fears' with regard to education, occupation and social status (Massey et al., 2008). However, it is important to note that the number of anxiety words was low across both groups. Thus, such explanations may account for why both groups exhibited similar levels of anxiety, but not why they exhibited similarly low levels of anxiety. Future research including measures of anxiety would allow for a more comprehensive understanding of the role of anxiety in linguistic expression amongst adolescents living with chronic pain and their peers.

Adolescents with CRPS used almost twice as many total cognitive words and a greater number of insight and discrepancy words. Insight here refers to words pertaining to self-appraisal, while discrepancy words pertain to lack of similarities between the self and others. These results can be explained from both a social comparison and a chronic pain perspective. It is well-documented that social comparison invokes both self-appraisal and attention to any perceived similarities or differences (Buunk \& Gibbons, 2007). Individuals with a chronic illness may be particularly vulnerable to the negative impact of social comparison due to heightened health uncertainty (Arigo et al., 2014). Furthermore, several studies have found that adolescents with chronic pain perceive themselves to be developmentally behind their peers in areas such as independence and identity formation, yet more able to cope with problems (Eccleston et al., 2008; Jordan et al., 2018). Taken together with our findings, this would suggest that adolescents living with chronic pain may engage more with important cognitive mechanisms, such as self-appraisal, particularly in social contexts where they compare themselves to their peers. This could confer either a disadvantage to the 
adolescent, through the negative impact of discrepant comparisons, or could confer an advantage on the adolescent, through greater insight and self-awareness. Future research is needed to test these hypotheses.

Despite the fact that fewer social words were observed, this difference did not reach significance and so our final hypothesis was not supported. This is at first glance a surprising result, given substantial literature suggesting impaired social functioning in adolescents with chronic pain (Forgeron et al., 2013; Forgeron et al., 2010). However, the quantitative nature of the LIWC means that it is unable to detect the valence of the social words (i.e. whether the adolescent was referring to a friend or family member in a positive or negative way), failing to capture the complexity and context of social language. Strength of peer relationships is an important factor that has previously been shown to be associated with positive social development and functional outcomes across multiple domains (Eccleston et al., 2008; La Buissoniere-Ariza et al., 2018). It could be that the sample of adolescents with CRPS in this study had strong peer and family relationships, leading to a more balanced use of social words between the two groups. Future research using the LIWC could apply other dimensions, such as the pronouns category, to explore adolescent's perceptions of romantic relationships, as use of first-person plural in romantic relationships have been reported to be associated with relationship quality and satisfaction (Tausczik \& Pennebaker, 2010). Alternatively, future research could analyse audio recorded verbal communication to extend coding of cognitive, affective and social dimensions to include relevant codes for tone and context.

There are several strengths of the current study. Firstly, the use of Social Comparison theory as a framework gives the study a strong theoretical foundation. Secondly, the methodology makes important contributions to the field of chronic pain, through both its demonstration of the utility of linguistic analysis approaches and through its emphasis on the flexibility of story completion methods. Despite this, the current study is not without limitations. No information was obtained from participants with CRPS in terms of type and duration of treatment. Such information may have influenced the adolescent's perceptions of their future and thus their language use. Furthermore, no maximum response length was set, which could have an impact on the results due to the likelihood of longer narratives having more words in each category. Lastly, the study adopted a cross-sectional design, thus no conclusions can be drawn regarding stability of adolescent's perceptions over time.

Despite these limitations, this study's findings could have important implications on the modification of psychosocial interventions. In light of these results, interventions could focus on increasing positive affect and mood, with the aim of promoting a more stable development trajectory for adolescents with CRPS. Indeed, the importance of affect as a treatment target is gaining increasing popularity through the efficacy of interventions such as Acceptance and Commitment Therapy, 
Dialectical Behaviour Therapy and Emotional Freedom Techniques (Coakley \& Wihak, 2017; Portelli, 2018). Interventions could also focus on identifying and promoting shared similarities between adolescents with CRPS and their peers without pain in a bid to reduce perceived differences and the subsequent negative influence of social comparisons on wellbeing. Future research could explore age, sex and gender differences, as differences in language use between boys/men and girls/women or across different age groups could have important implications, particularly for treatments that use language. To further extend the findings of this study, future studies could investigate whether these results are replicated in other chronic pain conditions, or combine the use of the LIWC with a qualitative approach, such as the 'think aloud' method (Eccles \& Arsal, 2017), in order to understand choice of narrative and to provide a holistic understanding of how adolescents with chronic pain use cognitive, affective and social language to describe their imagined futures.

\section{Conclusions}

The current study sought to explore the cognitive, affective and social language used by adolescents with CRPS when describing their future compared to their peers without pain. Adolescents with CRPS used fewer positive affect, greater negative affect and greater insight and discrepancy words compared with peers. Interestingly, adolescents with CRPS did not use fewer social words. These findings demonstrate the utility and flexibility of novel linguistic analyses in pediatric chronic pain research and highlight the importance of psychosocial factors as potential treatment targets in adolescents with chronic pain. Future studies could usefully integrate quantitative and qualitative methods to generate an in-depth understanding of how adolescents with CRPS think about their future selves.

\section{Acknowledgements}

We would like to thank the adolescents who participated in the study and CRPS organisations who supported the study through study recruitment advertisements. Thank you also to Tessa Rugg for helping with data collection for this project.

\section{Author Contributions}

E.N. conducted the analyses and took the lead on writing up the manuscript. L.C. developed the idea for the paper, reviewed the analyses and contributed to the write up of the findings. A.F.J ${ }^{\mathrm{a}}$. gathered the data, reviewed the analyses and contributed to the write up of the findings. E.F. reviewed the analyses and contributed to the write up of the findings. M.N. reviewed the analyses and contributed to the write up of the findings. A.L.J ${ }^{\mathrm{b}}$. developed the idea for the paper, reviewed the analyses and contributed to the write up of the findings. All authors discussed the results and commented on the manuscript. 
${ }^{a}$ Abigail Jones
${ }^{\mathrm{b}}$ Abbie Jordan

\section{References}

Abu-Arafeh, H., \& Abu-Arafeh. (2017). Complex regional pain syndrome in children: a systematic review of clinical features and movement disorders. Pain Management, 7(2). Available at: https://doi.org/10.2217/pmt-2016-0036

Arigo, D., Suls, J, M., \& Smyth, J, M. (2014). Social comparisons and chronic illness: A research synthesis and clinical implications. Health Psychology Review, 8(2), 154-214. https://doi.org/10.1080/17437199.2011.634572

Bantum, E, O., \& Owen, J, E. (2009). Evaluating the validity of computerized content analysis programs for identification of emotional expression in cancer narratives. Psychological Assessment, 21(1), 79-88. doi:10.1037/a0014643

La Buissonniere-Ariza, V., Hart, D., Schneider, S, C., McBride, N, M., Cepeda, S, L., ... \& Storch, E, A. (2018). Quality and correlates of peer relationships in youths with chronic pain. Child Psychiatry \& Human Development, 49(6), 865-874. https://doi.org/10.1007/s10578-018-0802-z

Buunk, A, P., \& Gibbons, F, X. (2007). Social comparisons: The end of a theory and the emergence of a field. Organizational Behaviour and Human Decision Processes, 102(1), 3-21.

Buunk, A, P., \& Ybemma, J, F. (1997). Social comparisons and occupational stress: The identification-contrast model. In B.P. Buunk \& F. X. Gibbons (Eds.) Health, coping, and well-being: Perspectives from social comparison theory (p.359-388). Mahwah, NJ: Erlbaum.

Candib, L, M. (2004). Making sense of my thumbs: Coming to terms with chronic illness. Families, Systems \& Health, 22(2), 139-151.

Clarke, V., Braun, V., Frith, H., \& Moller, N. (2019). Editorial Introduction to the Special Issue: Using Story Completion Methods in Qualitative Research. Qualitative Research in Psychology, 0(00), 1-20. https://doi.org/10.1080/14780887.2018.1536378

Clarke, V., Braun, V., \& Wooles, K. (2015). Thou shalt not covet another man? Exploring constructions of same-sex and different-sex infidelity. Journal of Community and Applied Social Psychology, 25(2), 153-166. https://doi.org/10.1002/casp.2204

Clarke, V., Hayfield, N., Moller, N., \& Irmgard, T. (2017). Once upon a time...: Story completion methods. In: V. Clarke et al. (Eds.). Collecting qualitative data: A practice guide to textual, media and virtual techniques. (pp. 45-70). Cambridge: Cambridge University Press.

Coakley, R., \& Wihak, T. (2017). Evidence-based psychological interventions for the management of pediatric chronic pain: New Directions in Research and Clinical Practice. Children, 4(2). Available at: doi:10.3390/children4020009 
Eccles, D, W., \& Arsal, G. (2017). The think aloud method: what is it and how do I use it? Qualitative Research in Sport, Exercise and Health, 9(4), 514-531.

https://doi.org/10.1080/2159676X.2017.1331501

Eccleston, C., Wastell, S., Crombez, G., \& Jordan, A. (2008). Adolescent social development and chronic pain. European Journal of Pain, 12(6), 764-774. https://doi.org/10.1016/j.ejpain.2007.11.002

Festinger, L. (1965). A theory of social comparison processes. Human Relations, 7, 117-140. https://doi.org/10.1177\%2F001872675400700202

Forgeron, P. A., Evans, J., McGrath, P. J., Stevens, B., \& Finley, G. A. (2013). Living with difference: Exploring the social self of adolescents with chronic pain. Pain Research \& Management, 18(6), 115-123. https://doi.org/10.1155/2013/120632

Forgeron, P., King, S., Stinson, J., McGrath, P., MacDonald, A., \& Chambers, C. (2010). Social functioning and peer relationships in children and adolescents with chronic pain: A systematic review. Pain Research and Management, 15(1), 27-41. https://doi.org/10.1155/2010/820407

Frank, A, W. (1993). The rhetoric of self change: Illness experience as narrative. Sociology Quarterly, 34(1), 39-52.

Frith, H. (2013). Accounting for organismic absence: exploring heterosex using the story completion method. Psychology and Sexuality, 4(3), 310-322. https://doi.org/10.1080/19419899.2012.760172

Hayfield, N., \& Wood, M. (2018). Looking heteronormatively good! Combining story completing with Bitstrips to explore understandings of sexuality and appearance. Qualitative Research in Psychology, 00(00), 1-21. https://doi.org/10.1080/14780887.2018.1536390

Jones, A., Caes, L., Eccleston, C., McMurtry, C.M., \& Jordan, A. (in press). Socio-developmental challenges faced by young people with chronic pain: A scoping review. Journal of Pediatric Pain.

Jones, K., Nordstrokke, D., Wilcox, G., Schroeder, M., \& Noel, M. (2018). The 'work of childhood': understanding school functioning in youth with chronic pain. Pain Management, 8(2), 139-153.

Jordan, A., Noel, M., Caes, L., Connell, H., \& Gauntlett-Gilbert. (2018). A developmental arrest? Interruption and identify in adolescent chronic pain. Pain Reports, 3(1), doi: 10.1097/PR9.0000000000000678

Junghaeunel, D, U., Schneider, S., \& Broderick, J, E. (2017). Linguistic indicators of pain catastrophizing in patients with chronic musculoskeletal pain. Journal of Pain, 18(5), 597-604. https://doi.org/10.1016/j.jpain.2017.01.001

Langer, S, L., Romano, J, M., Liu, Q., Levy, R, L., Neilson, H., \& Brown, J. (2016). Pain catastrophizing predicts verbal expression among children with chronic pain and their mothers. Health Psychology Open. Available at: https://doi.org/10.1177/2055102916632667

Logan, D, E., Williams, S, E., Carullo, V, P., Claar, R, L., Bruehl, S., \& Berde, C, B. (2013). Children and adolescents with complex regional pain syndrome: more psychologically distressed that other 
children in pain? Pain Research and Management, 18(2), 87-93.

https://doi.org/10.1155/2013/964352

Logan, D, E., Simons, L, E., Stein, M, J., \& Chastain, L. (2008). School impairment in adolescents with chronic pain. The Journal of Pain, 9(5), 407-416. doi.org\%2F10.1016\%2Fj.jpain.2007.12.003

Liossi, C., \& Howard, R, F. (2016). Pediatric chronic pain: Biopsychosocial assessment and formulation. Pediatrics, 138(5), e20160331. https://doi.org/10.1542/peds.2016-0331

Lumley, M, A., Cohen, J, L., Borszcz, G, S., Cano, A., Radcliffe, A, M., ... \& Keefe, F, J. (2011). Pain and emotion: A biopsychosocial review of recent research. Journal of Clinical Psychology, 67(9), 942-968. https://doi.org/10.1002/jclp.20816

Massey, E, K., Gebhardt, W, A., \& Garnefski, G. (2008). Adolescent goal content and pursuit: A review of the literature from the past 16 years. Developmental Review, 28(4), 421-460. https://doi.org/10.1016/j.dr.2008.03.002

Noel, M., Beals-Erikson, S, E., Law, E, F., Alberts, N., \& Palermo, T, M. (2016). Characterizing the pain narratives of parents of youth with chronic pain. Clinical Journal of Pain, 32(1), 849-858. doi: 10.1097/AJP.0000000000000346

Pennebaker, J, W., \& Francis, M, E. (1996). Cognitive, emotional and language processes in disclosure. Cognition and Emotion, 10(6), 601-626. https://doi.org/10.1080/026999396380079

Pennebaker, J. W., Booth, R. J., Boyd, R. L., \& Francis, M. E. (2015). Linguistic Inquiry and Word Count: LIWC2015. Austin, TX: Pennebaker Conglomerates (www.LIWC.net).

Portelli, P. (2018). Psychosocial interventions for pain management. Journal of Anaesthesiology and Critical Care, 1(1), 3. https://doi.org/10.1093/bja/aet129

Simons, L. (2017). Fear of pain in children and adolescents with neuropathic pain and CRPS. Pain, 157(1), 90-97.

Tausczik, Y, R., \& Pennebaker, J, W. (2010). The psychological meaning of words: LIWC and computerized text analysis methods. Journal of Language and Social Psychology, 29(1), 24-51. https://doi.org/10.1093/jpepsy/jsv029

Tran, S, T., Jastrowski, K, E., Hainsworth, K, R., Medrano, G, R., Anderson, K, K., Weisman, S, J., Davies, W, H. (2015). Distinct influences of anxiety and pain catastrophizing on functional outcomes in children and adolescents with chronic pain. Journal of Paediatric Psychology, 40(8), 744-755.

Walsh, E., \& Malson, H. (2010). Discursive constructions of eating disorders: A story completion task. Feminism and Psychology, 20(4), 529-537. https://doi.org/10.1177\%2F0959353509350759

Wright, L, J., Afari, N., \& Zautra, A. (2010). The illness uncertainty concept: A review. Current Pain and Headache Reports, 13(2), 113-138. https://doi.org/10.1007/s11916-009-0023-Z 
Table 1. Demographic characteristics for adolescents with CRPS and adolescents without pain. $\mathrm{M}=$ mean.

\begin{tabular}{lll}
\hline & \multicolumn{1}{c}{$\begin{array}{c}\text { Adolescents with CRPS } \\
(\mathrm{n}=49)\end{array}$} & $\begin{array}{c}\text { Adolescents without pain } \\
(\mathrm{n}=48)\end{array}$ \\
\hline Age & $\mathrm{M}=19.80, \mathrm{SD}=3.68$ & $\mathrm{M}=18.25, \mathrm{SD}=3.32$ \\
Sex & Females $=43$, Males $=5$ & Females $=37$, Males 11 \\
\hline Current Pain Intensity* & $\mathrm{M}=6.14, \mathrm{SD}=2.16$ & \\
\hline
\end{tabular}

*Measured using 11-point Numeric Pain Rating Scale (NPRS). '0' representing "No pain” and '10' representing "Worst possible pain". 
Table 2. Table presenting each LIWC dimension and subcategory used in the current study. Note: in certain instances, words can be coded in more than one dimension; for example, 'dad' would be coded as both family and male.

\begin{tabular}{lll}
\hline LIWC dimension & Definition & Example \\
\hline Affect processes & general words pertaining to affect & \\
\hline Positive emotion & word expressing positive emotions & love, nice, sweet \\
\hline Negative emotion & words expressing negative emotions & hurt, ugly, nasty \\
\hline \multicolumn{1}{c}{ Anxiety } & words expressing feelings of anxiety & worried, fearful \\
\hline Anger & words expressing feelings of anger & hate, kill, annoyed \\
\hline Sadness & words expressing feelings of sadness & crying, grief, sad \\
\hline Social processes & general words pertaining to social processes & \\
\hline Family & words pertaining to family & daughter, dad, aunt \\
\hline Friend & words pertaining to friends & buddy, neighbor, \\
& & friend \\
\hline Female & words pertaining to females & girl, her, mum \\
\hline Male & words pertaining to males & boy, his, dad \\
\hline Cognitive processes & general words pertaining to cognitive processes & \\
\hline Insight & words pertaining to self-appraisal & think, know, consider \\
\hline Causation & words pertaining to causal appraisal/relationships & because, effect, hence \\
\hline Discrepancy & words pertaining to discrepancies/lack of similarities & should, would, could \\
\hline Tentative & words pertaining to not certain, or not fixed; hesitant & maybe, perhaps \\
\hline Certainty & words pertaining to firm convictions, being assured & always, never \\
\hline Differentiation & words pertaining to distinguishing between two or & hasn't, but, else \\
\hline more things & \\
\hline
\end{tabular}


Table 3. Descriptive statistics (mean number of words, standard deviation, minimum and maximum) of LIWC dimensions for adolescents with CRPS and adolescents without pain.

\begin{tabular}{|c|c|c|c|c|c|}
\hline Dimension/Category & & $\mathrm{M}$ & SD & Minimum & Maximum \\
\hline \multirow[t]{3}{*}{ Total Cognitive } & CRPS & 12.77 & 4.13 & .00 & 20.83 \\
\hline & Pain-free & 8.95 & 5.32 & .00 & 18.37 \\
\hline & Total & 10.88 & 5.11 & & \\
\hline \multirow[t]{3}{*}{ Insight } & CRPS & 1.92 & 1.32 & .00 & 5.10 \\
\hline & Pain-free & 1.21 & 1.77 & .00 & 9.09 \\
\hline & Total & 1.57 & 1.59 & & \\
\hline \multirow[t]{3}{*}{ Discrepancies } & CRPS & 1.49 & .90 & .00 & 3.93 \\
\hline & Pain-free & .45 & .88 & .00 & 2.94 \\
\hline & Total & .98 & 1.03 & & \\
\hline \multirow[t]{3}{*}{ Tentative } & CRPS & 3.46 & 2.67 & .00 & 8.65 \\
\hline & Pain-free & 2.61 & 2.48 & .00 & 7.32 \\
\hline & Total & 3.04 & 2.40 & & \\
\hline \multirow[t]{3}{*}{ Certainty } & CRPS & 3.53 & 1.84 & .00 & 8.95 \\
\hline & Pain-free & 3.85 & 3.01 & .00 & 10.77 \\
\hline & Total & 3.69 & 2.48 & & \\
\hline \multirow[t]{3}{*}{ Differentiation } & CRPS & 1.16 & 1.06 & .00 & 4.76 \\
\hline & Pain-free & .84 & 1.34 & .00 & 6.06 \\
\hline & Total & 1.00 & 1.23 & & \\
\hline \multirow[t]{3}{*}{ Total Affect } & CRPS & 5.27 & 2.50 & .00 & 14.00 \\
\hline & Pain-free & 6.08 & 4.65 & .00 & 28.00 \\
\hline & Total & 5.67 & 3.73 & & \\
\hline \multirow[t]{3}{*}{ Positive Affect } & CRPS & 3.74 & 2.23 & .00 & 11.05 \\
\hline & Pain-free & 5.60 & 4.50 & .00 & 28.00 \\
\hline & Total & 4.66 & 3.64 & & \\
\hline \multirow[t]{3}{*}{ Negative Affect } & CRPS & 1.50 & 1.32 & .00 & 5.62 \\
\hline & Pain-free & .46 & 1.18 & .00 & 7.14 \\
\hline & Total & .98 & 1.35 & & \\
\hline \multirow[t]{3}{*}{ Anxiety } & CRPS & .33 & .43 & .00 & 1.61 \\
\hline & Pain-free & .31 & 1.11 & .00 & 7.14 \\
\hline & Total & .32 & .84 & & \\
\hline \multirow[t]{3}{*}{ Anger } & CRPS & .15 & .29 & .00 & 1.06 \\
\hline & Pain-free & .02 & .11 & .00 & .62 \\
\hline & Total & .09 & .22 & & \\
\hline
\end{tabular}




\begin{tabular}{|c|c|c|c|c|c|}
\hline \multirow[t]{3}{*}{ Sadness } & CRPS & .28 & .42 & .00 & 1.69 \\
\hline & Pain-free & .11 & .34 & .00 & 1.54 \\
\hline & Total & .20 & .39 & & \\
\hline \multirow[t]{3}{*}{ Total Social } & CPRS & 5.95 & 3.27 & .00 & 19.05 \\
\hline & Pain-free & 6.67 & 4.47 & .00 & 18.18 \\
\hline & Total & 6.31 & 3.90 & & \\
\hline \multirow[t]{3}{*}{ Family } & CRPS & .85 & 1.46 & .00 & 9.52 \\
\hline & Pain-free & 1.44 & 2.28 & .00 & 11.11 \\
\hline & Total & 1.14 & 1.93 & & \\
\hline \multirow[t]{3}{*}{ Friends } & CRPS & .64 & .76 & .00 & 4.76 \\
\hline & Pain-free & .71 & 1.20 & .00 & 5.56 \\
\hline & Total & .67 & 1.00 & & \\
\hline \multirow[t]{3}{*}{ Female } & CRPS & .28 & .76 & .00 & 4.76 \\
\hline & Pain-free & .22 & .95 & .00 & 6.33 \\
\hline & Total & .25 & .85 & & \\
\hline \multirow[t]{3}{*}{ Male } & CRPS & .27 & .51 & .00 & 2.19 \\
\hline & Pain-free & .33 & .99 & .00 & 5.56 \\
\hline & Total & .30 & .78 & & \\
\hline
\end{tabular}




\section{Figure 1}

Example stories from adolescents with CRPS

\section{Example story 1}

I aim in the future to be a paediatric nurse and help those with conditions such as CRPS. I will be a horse rider and have my own stables this will help to keep my legs (my effected CRPS area) moving and functioning. I will have passed all my GCSE's successfully. I will be able to live CRPS free and not be at risk of having a flare up every time I fall over. I would be like to own a variety of pets for therapeutic values. I aim to live independently and have my own apartment if I can afford it. I will be more comfortable in social situations and do things that challenge my anxieties (going on buses etc). I aim to have overcome the stresses of school I would like to be able to go out with friends and be sociable without letting anxiety get in the way and restrict social interaction. I would like to say I have helped others with CRPS and share ways I have dealt with my CRPS and treatments that have worked for me

\section{Example story 2}

In 10 years' time I hope to competed my degree and have made good contacts within the costume industry and be an established costume maker maybe a specialising in something like the breaking down of fabrics either working freelance or as part of a company such as the national theatre on their shows or making for new and renowned West End shows particularly musicals, or be working for a smaller independent theatre supporting local community's and have some free time to enjoy the shows and theatre performances which is something I love to do .I would also hope that I have my own place preferable still within London which I either rent or mortgage and has space of a room for a studio to do my work 
in which would be extremely important if I was working freelance as this would be my work place essentially. I would also like to still have a good support network of friends that I know from different places to ensure I don't get to engrossed in work life and family whom I think are very important part of my life and I hold great value on their opinions and I always strive to make them proud. I also would like to be able to have better pain management in order to be able to manage my job and personal life better without feeling the effects as often as currently I still struggle after over working myself, but I'm a true believer in that if I have the right help and support I will be able to cope better and not let its overtake my life

*Potentially identifying details removed from stories as presented here. 


\section{Figure 2}

Example stories from adolescents without pain

\section{Example 1}

Making use of the history degree I am about to study and enjoying a job related to that degree. Having kept contact with friends I feel bring the best out of me and motivate me to do better in all aspects of life. Seeing more of the world outside Scotland and taking opportunities as they come to become more knowledgeable about other cultures and countries. Working abroad to learn new experiences and meeting new people. stepping out of my comfort zone and be more confident with myself and my actions. Taking more time to prioritise my mental health and learn that it is important to do so consistently. Becoming a better person and keeping morals and principles I feel should be spoken about. Using university as way to learn more about myself, my work ethic and what truly interests me and have the courage to pursue those interests, even if it means changing degree, taking a year out and going abroad/working or not go back at all and reach my goals another way.

Not having kept friendships/relationships for convenience and actually put energy into ones that matter most and will make me happy, instead being scared about hurting feelings/ confrontation.

\section{Example story 2}

I hope to have graduated from university with a degree, hopefully a masters. This will have enabled me to find a stable job which I enjoy. I hope to have a healthy relationship with at least one child or plans of having children soon. I aspire to have saved enough money at this point to be living comfortably and give my children a comfortable life. I have always 
dreamed of living in an old fashioned house with modern interior. I hope to have worked my way up to a managerial position in my career as this is largely what the degree I am going to study is based on. Most importantly I hope to have a long healthy life and not suffer from any major physical or mental illnesses which stop me from achieving these goals as dementia is present in my family history. 